\title{
FREQUENCY OF GENITAL TRACT TRAUMA DURING VAGINAL BIRTH IN PRIMIGRAVIDA AT TERTIARY CARE HOSPITAL OF QUETTA.
}

1. MBBS, FCPS

Senior Registrar Gynecology Bolan Medical Complex Hospital Quetta.

2. MBBS, FCPS

Assistant Professor Gynecology Bolan Medical Complex Hospital, Quetta.

3. MBBS, FCPS

Senior Registrar Gynecology Bolan Medical Complex Hospital Quetta.

4. MBBS, FCPS

Assistant Professor Radiology Bolan Medical Complex Hospital, Quetta.

Correspondence Address:

Dr. Shama Jogezai

Senior Registrar Gynecology

Bolan Medical Complex Hospital,

Quetta.

galokhan@hotmail.com

Article received on:

08/05/2019

Accepted for publication:

24/10/2019

\section{INTRODUCTION}

Pregnancy and childbirth involve significant health risks, even for women with no preexisting health problems. Approximately 40 percent of pregnant women experience pregnancy-related health problems, and 15 percent of all pregnant women suffer long-term or life-threatening complications.

Normal labor and parturition can be pleasurable event for mothers. The joy of receiving a healthy baby is further increased if the mother is comfortable, healthy and physically fit. On the other hand, if mother sustains some type of physical or psychological trauma during labor, it will lead to marked distress and the puerperium becomes uncomfortable.

Genital tract trauma is very common with spontaneous vaginal birth. Approximately $20 \%$ of all women experience some trauma out of which $34 \%$ are primigravida. These tears comprise of 1 st degree in $18.8 \%$, 2nd degree in $29 \%$, 3rd degree

\section{in $0.2 \%{ }^{1}$}

These injuries can lead to short term and long term morbidity for new mothers. Short term problem include blood loss, need for suturing and perineal pain. Long term complications may include extended pain and various functional difficulties such as bowel, urinary and coital problems. ${ }^{2}$

Genital tract trauma is more likely to occur in precipitate, uncontrolled or unsupervised delivery, instrumental delivery, delivery of a good size infant and injudicious use of oxytocin or presence of a scar anywhere in the genital tract. ${ }^{3}$

Obstetrical Haemorrhage is the leading cause of maternal mortality world wide. ${ }^{4}$ Genital tract trauma accounts for $29 \%$ of such cases. These traumas include cervical tears, vaginal tears, perineal tears and uterine rupture. ${ }^{5} \mathrm{~A}$ study conducted in Pakistan revealed that in $33 \%$ of patients with 
post-partum Haemorrhage, the cause was genital tract trauma. ${ }^{6}$

Perineal injury can occur in normal vaginal deliveries and is the leading cause of fecal incontinence. This can have devastating effect on the quality of life. Up to $10 \%$ women develop symptoms of fecal urgency or incontinence after their first vaginal delivery. ${ }^{7}$

Anal sphincter rupture is reported in about $2.5 \%$ of vaginal deliveries where mediolateral episiotomy is performed and $11 \%$ where midline episiotomy is practiced. These injuries are the most common cause of fecal incontinence in women. ${ }^{8}$ The effect of parturition on the pelvic floor is now well documented and attention is now increasingly focused on the prevention of pelvic floor damage..$^{9,10}$

Genital tract trauma leads to serious complication however no study has been conducted in Balochistan regarding the type and frequency of such trauma. Balochistan is the largest province of Pakistan with low access to health care; hence it is important to know the magnitude of the problem in patients who even manage to come to hospital for delivery. This study will also help us to compare the magnitude of the problem in Balochistan with other parts of the world as well as our country.

\section{MATERIAL \& METHODS}

It was a cross sectional study conducted in the Department of Obstetrics and Gynecology, Bolan Medical Complex Hospital Quetta from $1^{\text {st }}$ September 2018 to $31^{\text {st }}$ March 2019. A total of 127 primigravida were included in the study, with vertex presentation. Sample technique was Nonprobability purposive.

Inclusion Criteria was Primigravida, Pregnancy of 37 to 40 weeks determined by asking lastmenstrual period and vertex presentation. Exclusion Criteria was Multigravida, all presentations other than vertex, Instrumental delivery, Primigravida with cephalopelvic disproportion, Placenta previa type III and IV determined by ultrasound, large size baby, Diabetic mother, anemic mother.
Primigravida who were in labor, admitted through outpatient department or emergency, meeting the inclusion criteria were enrolled in the study and informed consent was taken. Exclusion criteria were strictly followed to avoid confounding variables. Relevant history regarding duration of gestation was taken. Patients were managed and monitored during first and second stage of labor. After spontaneous vaginal delivery patients were examined for any type of trauma. Repair of the trauma was carried out. Presence of trauma and type of trauma were recorded in a specially designed proforma.

Data was entered and analyzed in the statistical software, SPSS-20 "Statistical Package for Social Sciences". Frequency and percentage were computed for categorical variables like genital tract trauma, type of genital tract trauma, episiotomy. Mean, standard deviation, 95\% confidence interval, median and inter quartile range were estimated for age, gestational age, height and weight. A stratification technique was used to control confounding factors like age, weight and height to observed effect on outcome variables. A total of 127 Primigravida with vertex presentation were randomly included in the study. Frequency and percentages were calculated for genital tract trauma, type of trauma and episiotomy.

\section{RESULTS}

A total of 127 pregnant primigravida with vertex presentation were included in this study. The average age of the patients was $22.83 \pm 3.73$ years (95\% Cl: 22.18 to23.49). Frequency of genital tract trauma with age distribution is presented in Figure-1.

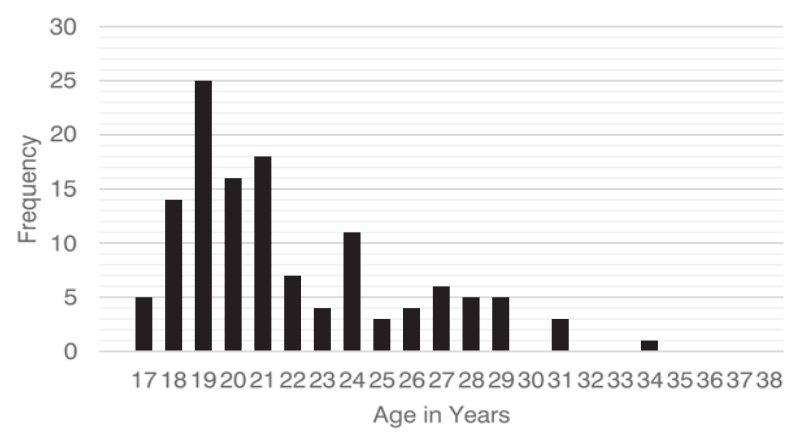

Figure-1. Frequency of genital tract trauma with age distribution of the patients $n=127$ 
The average gestational age of the patients was $38.16 \pm 0.98$ weeks $(95 \% \mathrm{Cl}: 37.98$ to38.33) and average height and weight of the patients presented in Table-l.

Frequency of genital tract trauma in patients with spontaneous vertex delivery in primigravida was observed in $40(31 \%)$ cases. Perineal tear was observed in $90 \%$ (36/40) and cervical tear was observed in $10 \%(4 / 40)$ cases. $1^{\text {st }}$ degree of perineal tear was seen in $17(47 \%), 2^{\text {nd }}$ degree $18(50 \%)$ and one case with $3^{\text {rd }}$ degree perineal tear.

Of the 127 patients, 43.2\% (19/44) were below 21 years of age, $22.8 \%$ (18/79) were between 21 to 30 years of age and $78 \%(3 / 4))$ were above 30 years of age. Similarly type of genital tract trauma with respect to age is shown in Table-II. 32.4\% (12/37) were below $156 \mathrm{~cm}$ of height, $28.6 \%$ (18/63) were between 156 to $163 \mathrm{~cm}$ and 37\% (10/27) were above $163 \mathrm{~cm}$ of height.

$30.6 \%(22 / 72)$ were below $61 \mathrm{~kg}$ of weight, $29.3 \%$ (12/41) were between 61 to $66 \mathrm{~kg}$ and $42.9 \%$ (6/14) were above $66 \mathrm{~kg}$ of weight. Similarly type of genital tract trauma with respect to weight of patients is shown in Table-III.

\section{DISCUSSION}

Pregnancy and child birth involve significant health risks, even for women with no pre-existing health problem. Women experience joy, happiness and relief on the birth of their child. On the other hand, if she has under gone some type of psychological or physical trauma, these emotions are replaced by fatigue, pain and depression. ${ }^{11}$

Millions of women give birth vaginally each year and genital tract trauma is a common outcome of this vaginal birth. Atleast 12 million women a year, sustain some kind of damage during pregnancy and child birth that will have profound effect on their lives. ${ }^{12}$ This trauma comprises of tears and lacerations of perineum, cervix and uterus such can lead to blood loss, need for suturing, perineal pain, urinary and fecal incontinence. ${ }^{13}$

In our study $31 \%$ of women had genital tract trauma after spontaneous vertex vaginal delivery. This is comparable with the results of Albers LL et al where genital tract trauma was seen in $34 \%$ of nulliparous women. ${ }^{1}$

\begin{tabular}{|l|c|c|c|c|}
\hline \multicolumn{1}{|c|}{ Variables } & Mean \pm SD & $95 \%$ CI & Median (IQR) & Maximum - inimum \\
\hline Age (Years) & $22.83 \pm 3.73$ & 22.18 to23.49 & $22(6)$ & $35-18$ \\
\hline Gestational Age (Weeks) & $38.16 \pm 0.98$ & 37.98 to38.33 & $38(2)$ & $40-37$ \\
\hline Height & $158.09 \pm 10.49$ & 156.24 to159.93 & $160(7)$ & $170-155$ \\
\hline Weight & $60.87 \pm 4.43$ & 60.10 to61.65 & $60(6)$ & $72-50$ \\
\hline
\end{tabular}

Table-I. Descriptive statistics of characteristics of patients.

\begin{tabular}{|c|c|c|c|c|}
\hline \multirow{2}{*}{ Age Groups } & \multicolumn{3}{|c|}{ Perineal Tear } & \multirow{2}{*}{ Cervical Tear } \\
\hline & $1^{\text {st }}$ Degree & $2^{\text {nd }}$ Degree & $3^{\text {rd }}$ Degree & \\
\hline$\leq 20$ Years & 8 & 8 & 0 & 3 \\
\hline$>30$ Years & 2 & 1 & 0 & 0 \\
\hline
\end{tabular}

\begin{tabular}{|c|c|c|c|c|}
\hline Weight & \multicolumn{3}{|c|}{ Perineal Tear } & Cervical Tear \\
\hline$\leq 60 \mathrm{~kg}$ & 12 & 8 & 0 & 2 \\
\hline 61 to 66 & 5 & 5 & 0 & 2 \\
\hline Above 66 & 0 & 5 & 1 & 0 \\
\hline
\end{tabular}


These finding are also consistent with the finding of Saba $\mathrm{N}$ et al. ${ }^{14} \mathrm{On}$ the other hand Brohi ZP et $\mathrm{al}^{15}$ reported perineal tear frequency of $9.8 \%$. Regarding the type of trauma $90 \%$ had perineal tear and $10 \%$ suffered cervical tear, whereas no uterine rupture found.

1st degree perineal tear was seen in $47 \%$ while 2 nd in $50 \%$ of women. These finding are slightly higher than the finding of Samuellsson $E$ et al where 1st degree perineal tear was seen in 34\% while 2 nd degree perineal tear in $38 \%$ of cases. ${ }^{16}$

There was only one case of third degree perineal tear whereas no fourth degree perineal tear was found. So third degree perineal tear comprises $3 \%$ of the cases. These are consistent with the international literature where the incidence is 0.6$2.5 \%{ }^{17}$ while Rizvi FM et al found this trauma only in $0.5 \%$ of cases which could be due to under reporting in our setup and missed diagnosis of 3a grade of 3rd degree tear which is labeled as 2 nd degree tear. ${ }^{18}$ Cervical tear was found in $10 \%$ of women after delivery which is much lower than the incidence of such trauma found by Bibi $S$ et al. ${ }^{19}$

There was no case of uterine rupture in our study. This is because uterus of primigravida is considered immune to rupture but literature has shown many cases where uterine rupture occurred in primigravidas. ${ }^{20,21,22}$

Episiotomy, which is an iatrogenic genital tract trauma was practiced for $100 \%$, women undergoing their first vaginal birth from 19401990. But for the last few decades its liberal use has declined. $40 \%$ of patients received episiotomy as it is regarded as a protective procedure against perineal trauma. Many studies have been conducted, concerning outcome of liberal versus restricted use of episiotomy Frankman EA et al ${ }^{23}$ suggest $20-40 \%$ episiotomy rate. In our setup also a study by Mehrunisa at Lady Willington Hospital24 $^{24}$ has found no significant protective effect of episiotomy against severe perineal lacerations. But Naseem S et $\mathrm{al}^{14}$, Al-Ghammari K et $\mathrm{al}^{25}$, and Venus $\mathrm{D}$ et $\mathrm{al}^{26}$ has supported the use of mediolateral episiotomy for the prevention of obstetrical perineal injuries.
In our study it was found that majority of women were in 20-29 years age group. This is because it is the peak reproductive age group. There were only 4 women who were above 30 years and 3 out of those 4 got genital tract trauma. This shows that older age group is associated with increased risk of trauma while Dahl $\mathrm{C}$ et al ${ }^{27}$ has failed to show any association of advanced maternal age with genital tract trauma.

In this study $42.9 \%$ patients were having weight more than $66 \mathrm{~kg}$. This shows that higher body mass index is associated with increased risk of birth trauma. This is also supported by a study by Albers LL et al. ${ }^{28}$

\section{CONCLUSION}

It is difficult to reduce the frequency of genital tract trauma after vaginal birth in primigravida. There is need for more research work on how to reduce the frequency of birth trauma. Different techniques are suggested to be worked on like antenatal perineal massage, warm compresses, massage with lubricant and Hands off method during second stage of labor. Further information on techniques to protect the perineum during spontaneous delivery is surely needed. Mediolateral episiotomy appears to be protective against perineal trauma but its use should be restrictive.

Copyright $(24$ Oct, 2019.

\section{REFERENCES}

1. Albers LL, Sedler KD, Bedrick EJ, Teaf D, Peralta P. Factors related to genital tract trauma in normal spontaneous vaginal births. Birth. 2006; 33:94-100.

2. Albers LL, Borders N. Minimizing genital tract trauma and related pain following spontaneous vaginal birth. J Midwifery Womens Health. 2007; 52:246-53.

3. Poggi SB, Kapernick PS. Postpartum hemorrhage and abnormal puerperium. In: DeCherney AH, Nathan L, editors. Current obstetric \& gynecological diagnosis \& treatment. USA: McGraw-Hill; 2003. p. 531-52.

4. Oyelese Y, Ananth CV. Postpartum hemorrhage: Epidemiology, risk factors, and causes. Clin Obstet Gynecol. 2010; 53:147-56.

5. Ejaz L, Rasheed N. Post-Partum Haemorrhage analysis of 108 cases. J Surg. 2001; 21-22:14-8 
6. Chohan A, Butt F, Mansoor H, Falak T. Primary postpartum hemorrhage: Outcome of different treatment measures. Biomedica. 2006; 22:16-20.

7. Burgio $\mathrm{KL}$, Borello-France $\mathrm{D}$, Richter HE, Fitzgerald MP, Whitehead W, Handa VL, et al. Risk factors for fecal and urinary incontinence after childbirth: The childbirth and pelvic symptoms study. Am J Gastroenterol. 2007; 102:1998-2004.

8. Dudding TC, Vaizey CJ, Kamm MA. Obstetric anal sphincter injury: Incidence, risk factors, and management. Ann Surg. 2008; 247:224-37.

9. Arulkumaran S. Mal presentations, malposition, cephalopelvic disproportion and obstetric procedures. In: Edmonds DK, editor. Dewhursts text book of obstetrics and gynecology. Oxford: WielyBlackwell; 2007.p. 213-26

10. Stepp KJ, Siddiqui NY, Emery SP, Barber MD. Textbook recommendations for preventing and treating perineal injury at vaginal delivery. Obstet Gynecol. 2006; 107(2 Pt 1):361-6.

11. Mirza FG, Gaddipati S. Obstetric emergencies. Semin Perinatol. 2009; 33:97-103.

12. Premkumar G. Perineal trauma reducing associated postnatal maternal morbidity. RCM Midwives. 2005; 8:30-2.

13. Borders N. After the afterbirth: A critical review of postpartum health relative to method of delivery. $J$ Midwifery Womens Health. 2006; 51:242-8.

14. Saba N, Sultana A, Afridi M. Obstetric perineal injuries. Pak J Med Health Sci. 2007; 1:86-8.

15. Brohi ZP, Sadaf A, Zohra N, Perveen U. Frequency and severity of perineal tears in Coutess Lady Duffrin Flud Hospital, Hyderabad. J Pak Med Assoc. 2012 Aug; 62(8):803-6.

16. Samuelsson E, Ladfors L, Lindblom BG, Hagberg $H$. A prospective observational study on tears during vaginal delivery: Occurrences and risk factors. Acta Obstet Gynecol Scand. 2002; 81:44-9.

17. Romano AM. Research summaries for normal birth. $\mathrm{J}$ Perinat Educ. 2007; 16:53-8.
18. Rizvi RM, Chaudhury N. Practices regarding diagnosis and management of third and fourth degree perineal tears. J Pak Med Assoc. 2008; 58:244-7.

19. Bibi S, Danish N, Fawad A, Jamil M. An audit of primary post-partum hemorrhage. J Ayub Med Coll Abottabad. 2007; 19:102-6.

20. Walsh CA, Baxi LV. Rupture of the primigravid uterus: A review of the literature. Obstet Gynecol Surv. 2007; 62:327-34; quiz 353-4.

21. Walsh CA, O'Sullivan RJ, Foley ME. Unexplained prelabor uterine rupture in a term primigravida. Obstet Gynecol. 2006; 108(3 Pt 2):725-7.

22. Musa J, Misauno MA. Uterine rupture in a primigravida presenting as an acute abdomen post-delivery: a case report. Niger J Med. 2007; 16:274-6.

23. Frankman EA, Wang L, Bunder $\mathrm{CH}$, Lowder JL. Episiotomy in the United States: Has anything changed? Am J Obstet Gynecol 2009; 200(5) el-7.

24. Meherun Nisa. Effect of episiotomy on perineal lacerations in spontaneous vertex deliveries. Ann King Edward Med Coll. 2005; 11:442-5.

25. Al-Ghammari K, Al-Riyami Z, Al-Moqbali M, Al-Marjabi F, Al-Mahrouqi B, Al-Khatri A, et al. Predictors of routine episiotomy in primigravida women in Oman. Appl Nurs Res. 2016; 29:131-5.

26. Venus D, P S R. Prajwal S. Comparison of use of restrictive episiotomy versus routine episiotomy in primigravida undergoing vaginal birth at a tertiary care hospital. Int J Reprod Contracept Obstet Gynecol. 2017 May; 6(5):1770-1776.

27. Dahl $\mathrm{C}, \mathrm{K}$ jolhede $\mathrm{P}$. Obstetric anal sphincter rupture in older primiparous women 'a case control study. Acta Obstet Gynecol Scand. 2006; 85(10):1252-8.

28. Albers LL, Greulich B, Peralta P. Body mass index, midwifery intrapartum care, and childbirth lacerations. J Midwifery Womens Health. 2006; 51:24953. 


\begin{tabular}{|l|l|l|}
\hline \multicolumn{3}{|c}{ AUTHORSHIP AND CONTRIBUTION DECLARATION } \\
\hline Sr. \# & \multicolumn{1}{|c|}{ Author(s) Full Name } & \multicolumn{1}{c}{ Contribution to the paper } \\
\hline 1 & Shama Jogezai & $\begin{array}{l}\text { Study design and concept, } \\
\text { questionnaire design, data } \\
\text { collection, Data analysis, } \\
\text { manuscript writing, manuscript } \\
\text { review. } \\
\text { Study design and concept, } \\
\text { questionnaire design, data } \\
\text { collection, Data analysis, } \\
\text { manuscript review. } \\
\text { Study design and concept, } \\
\text { questionnaire design, data } \\
\text { collection, Data analysis, } \\
\text { manuscript review. } \\
\text { Data collection, data analysis, } \\
\text { manuscript writing, manuscript } \\
\text { review. }\end{array}$ \\
\hline Rukhshanda Mushtaq
\end{tabular}

